\title{
PREVALÊNCIA DA INFECÇÃO PELO VÍRUS DA LEUCOSE DOS BOVINOS EM REBANHOS LEITEIROS CRIADOS NO ESTADO DO AMAZONAS, BRASIL
}

\author{
Paulo Alex Machado CARNEIRO; Wanderley Pereira de ARAÚJO3; \\ Eduardo Harry BIRGEL; ${ }^{3}$ Kleberson Worslley de SOUZA.
}

RESUMO: Determinou-se a prevalência de anticorpos séricos anti-Vírus da Leucose dos Bovinos (anti-VLB) em 661 amostras de soro sangüíneo, colhidas em 16 rebanhos leiteiros criados em quatro municípios da Microrregiāo de Manaus, no Estado do Amazonas (Manaus, Iranduba, Autazes e Careiro da Várzea). Para deteç̧ão de anticorpos anti-VLB utilizou-se o teste de Imunodifusão Radial Dupla de Ouchterlony em gel de ágar, com uso do antígeno glicoprotéico (gp-51) da cápsula do vírus. Os resultados demonstraram a ocorrência da Leucose Enzoótica dos Bovinos nos rebanhos estudados, sendo a taxa de prevalência de anticorpos séricos anti-VLB na população examinada igual a 8,9\% (59/661), com a exclusão dos animais com menos de seis meses de idade, nos quais a sororeação positiva poderia representar transferência passiva de anticorpos colostrais, verificou-se uma taxa de prevalência da infecçāo igual a 9,6\% (58/604). Os animais avaliados, foram estratificados em grupos de acordo com a faixa etária e sexo. A análise dos resultados obtidos, pelo teste de duas proporções, permitiu concluir que a prevalência de bovinos portadores de anticorpos anti-VLB foi significativamente maior nos animais com mais de 12 meses de idade, nāo havendo diferenças significativas nos resultados obtidos entre machos e fêmeas.

PALAVRAS-CHAVE: Leucose bovina, Leucose, Prevalência de doença, Amazonas, Bovino leiteiro

\section{PREVALENCE OF INFECTIONS WITH BOVINE LEUKOSIS VIRUS, IN DAIRY CATTLE RAISED IN AMAZONAS STATE, BRAZIL}

ABSTRACT : The prevalence of bovine leukaemia virus (BLV) was determined, through the anti-BLV serum antibody test, in 661 samples collected in 16 dairy herds from four municipalities in the micro region of Manaus, at the Amazonas state. The agar gel immunodiffusion test with an envelop glycoprotein virus-antigen (gp-51) was used as a method of diagnosis the infection or the presence of anti-BLV antibodies transferred passively by the colostrum to calves up to six- month-old.. 11 herds were positive for the BLV test. The overall prevalence was $8.9 \%$. When the calves less than six-month-old were excluded a rate

\footnotetext{
${ }^{1}$ Parte de Dissertação de Mestrado FMNZ - USP.

${ }^{2}$ Escola Agroténica Foderal de Mhnus. Alameda Come Ferreira, 8045, São José Cperário, Mknuus, AM. 59083-000 ${ }^{3}$ Departanento de Clirica Médica, Faculdade de Medicira Veterinária e Zoctecria, Universidade de Säo Paulo, Av. Prof. Dr. Orlardo Marques de Paiva, 87, São Paulo, SP. 05508-900
} 
of $9.6 \%(58 / 604)$ infection prevalence was found. The influence of the age and sex factors on the prevalence of BLV were analysed by the two-proportion test. Higher prevalence rate was found in cattle older than 12-month-old as compared to the younger calves. No sexual effect was found.

KEYWORDS: Bovine Leukosis Virus, Prevalence, Dairy cattle, Amazonas state, Brasil

\section{INTRODUÇÃO}

A Leucose Enzoótica dos Bovinos (LEB), é uma enfermidade infecto-contagiosa, determinada por retrovírus caracterizada por proliferação linfocitária e/ou formação de linfossarcomas (Ferrer, 1980). O desenvolvimento de linfossarcomas em sua evolução, invariavelmente resulta na morte do animal, demonstrando intensa infiltraçāo linfocitária em órgãos hemocitopoiéticos (linfonodos e baço), bem como nos órgãos ricos em tecido reticulo-histiocitário (abomaso, coração, rins, fígado e músculos), determinando um quadro sintomático pleomórfico (Birgel, 1982).

Apesar do Vírus da Leucose dos Bovinos (VLB) apresentar grande letalidade, as evidências têm comprovado que apenas uma pequena parcela dos animais infectados, desenvolvem uma das formas clínicas da doença (Ferrer et al., 1979; Burny et al., 1985); sendo a LEB considerada atualmente uma enfermidade de grande potencial de infecciosidade, especialmente entre bovinos produtores de leite, devido às condições de criação a que são submetidos.

O impacto econômico ocasionado pela LEB, em rebanhos leiteiros comerciais, tem sido constantemente relatado por diversos trabalhos científicos (Sorensen, 1979; Birgel et al., 1983; Thurmond, 1987; Johnson \& Kaneene, 1991b; 1992; Pollari et al., 1993; Garcia et al., 1995), e revistas de divulgação técnica (Oliveira, 1985; Jordão, 1986; 1987; Ereno, 1988; Martins,
1989). As perdas financeiras incluem, gastos com tratamento e diagnóstico, reduçāo dos níveis de produtividade, mortes de animais ocasionadas pela doença, condenação de carcaças, custos com a reposição de animais, e principalmente, a impossibilidade de exportação de animais.

De ocorrência inicialmente restrita a rebanhos criados a oeste do rio Elba, na Alemanha, a leucose dos bovinos se disseminou na Europa graças a grande movimentaçāo de animais entre paises, atingindo o auge após a Segunda Grande Guerra Mundial, em seguida, difundiu-se para outros continentes através da importação de animais, sendo considerada atualmente como uma doença cosmopolita, acometendo principalmente os rebanhos leiteiros (Olson \& Miller, 1987; Lorenz \& Straub, 1987; D'Angelino, 1991)

A introdução do VLB em rebanhos brasileiros foi atribuída a importação indiscriminada de bovinos do hemisfério norte, por pecuaristas de gado de elite das regiões Sudeste e Sul. Uma vez estabelecida, nessas regiōes, a LEB se disseminou para as regiōes Norte e Nordeste favorecida pelo trânsito intenso de animais (Abreu et al., 1994) e, principalmente, pela ausência de uma política sanitária visando combater a disseminação da doença em território nacional (Garcia et al., 1991).

Os levantamentos soroepide-miológicos da enfermidade tem sido freqüentes nas ultimas décadas sendo a situação bastante conhecida nas regiões Sul (Scarci et al., 1980; Kantec et 
al., 1983; Gomes et al., 1985; Flores et al., 1988; Flores et al., 1990; Carvalho, 1994), Sudeste (Alencar et al., 1979; Leite et al., 1980; Modena, 1981; Romero \& Rowe, 1981; Cunha et al., 1982; Birgel et al., 1982; Modena et al., 1984; Santos et al., 1985; Birgel et al., 1988; Birgel et al., 1991; D'Angelino, 1991; Birgel et al., 1993; Birgel Junior et al., 1995; Birgel et al., 1996; Melo et al., 1999), Centro-oeste (Andrade \& Almeida, 1991) e Nordeste (Tavora \& Birgel, 1991; Melo, 1991; Abreu, 1993; Birgel et al., 1999).

Na Região Norte, o primeiro relato de Leucose dos Bovinos foi assinalado no Estado do Amazonas em 1982 (Brasil, 1983). Posteriormente, Abreu (1990), realizou, nos Estados do Acre e Rondônia, o primeiro levantamento imunosorológico da infecção na Região e recentemente Molnar et al. (1999), publicaram os primeiros índices de prevalência da infecção pelo VLB no Estado do Pará. Entretanto, decorridos cerca de vinte anos do primeiro relato da enfermidade na regiāo, a real situação da LEB no maior Estado do país permanecia ainda desconhecida.

No esforço de contribuir para melhorar a realidade sanitária da pecuária bovina no Estado do Amazonas, oferecendo significativas informações clinico-epidemiologicas da infecção pela LEB na região, o presente trabalho teve como objetivo primordial, determinar a prevalência da infecção pelo Vírus da Leucose dos Bovinos em rebanhos leiteiros criados na Microrregião de Manaus, avaliando também, a influencia de fatores etários, sexuais sobre os índices de prevalência.

\section{MATERIAL E MÉTODOS}

Para realizar este estudo clinico epidemiológico de forma a estabelecer a prevalência de anticorpos séricos anti-VLB em rebanhos de bovinos leiteiros criados na Microrregião de Manaus, Estado do Amazonas, bem como avaliar a possível influência dos fatores etários e sexuais sobre os índices da infecçāo pelo VLB, foram colhidas amostras sangüíneas de 661 bovinos procedentes de 16 rebanhos, criados e mantidos em 4 municípios (Manaus, Iranduba, Autazes e Careiro da Várzea), no período de janeiro a março de 1999. Os animais foram sorteados ao acaso e classificados de acordo com a idade, sexo e manejo de criação e sanitário ao qual eram submetidos.

O tamanho da amostra, de 525 bovinos, foi determinado segundo os procedimentos indicados pelo Centro Pan-americano de Zoonoses (Cepanzo, 1979), para estudo da prevalência de enfermidades crônicas por amostragem. Para se estabelecer este valor estimou-se em $16 \%$ a prevalência da LEB no Estado do Amazonas, considerando-se valores médios obtidos em levantamentos sorológicos semelhantes realizados em outros Estados da Região Norte do Brasil, (Abreu, 1990). Como margem de segurança incluíram-se 136 amostras, atingindo, portanto, uma populaçāo de 661 animais.

As amostras de sangue foram colhidas por punção da veia jugular, com sistema de colheita a vácuo ${ }^{4}, \mathrm{em}$ tubos siliconizados com capacidade para $10 \mathrm{ml}$. O material colhido era mantido em temperatura ambiente até a retração do coágulo sangüíneo, em seguida sendo transportadas ao laboratório sob refrigeração, onde eram centrifugadas, durante 15 minutos, com força real de centrifugação igual a 1000 G. O soro obtido era então transferido para tubos de plástico sendo armazenados em congelador a $-20^{\circ} \mathrm{C}$, até o momento da realização dos testes sorológicos no Laboratório de Imunologia do Departamento de Clínica Médica da Faculdade

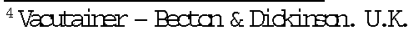


de Medicina Veterinária e Zootecnia da Universidade de São Paulo.

A detecção de anticorpos séricos antiVírus da Leucose dos Bovinos foi feita através da prova de imunodifusão radial dupla de Ouchterlony em gel de ágar, utilizando-se o antígeno glicoprotéico (gp 51) ${ }^{5}$ da cápsula do viral, segundo metodologia padronizada por Birgel (1982) e modificada por D’Angelino (1991).

O tipo de exploração pecuária adotada nas propriedades estudadas, era predominantemente leiteiro, com produção de leite tipo $C$ e média de cinco litros por dia. Entre os bovinos sorteados para formarem a populaçāo desta pesquisa incluíam-se 542 fêmeas e 119 machos, pertencentes a diversas raças européias e indianas e, principalmente, espécimes resultantes do cruzamento Bos taurus x Bos indicus. Os estados de Rondônia, Minas Gerais e São Paulo foram identificados como os principais exportadores de reprodutores e matrizes para os rebanhos estudados, entre as raças introduzidas predominavam Girolando, Gir e Holandesa.

Buscando-se verificar a existência de diferenças entre os resultados que pudessem ser atribuídas às influencias do sexo e da e faixa etária, os animais foram distribuídos em grupos experimentais avaliando os resultados pelo "Teste de duas proporções" com aproximação pela distribuição normal de probabilidade, ao nível de significância de $5 \%(\mathrm{a}=0.05)$ com o valor crítico de $Z=1,96$, conforme recomendam Berquo et al. (1981).

\section{RESULTADOS}

$\mathrm{Na}$ Tabela 1, destacaram-se os resultados obtidos na amostragem total, caracterizando as amostras reagentes e não reagentes ao teste de IDLB, apresentando os valores absolutos e relativos. Verificou-se que das 661 amostras de soro colhidas de bovinos leiteiros criados na Microrregião de Manaus, 59 amostras (8,9\%) reagiram positivamente na prova de IDLB.

Na Tabela 2 apresentaram-se as taxas de prevalência de anticorpos anti-VLB, expressando a frequiência em números absolutos e relativos, distribuídas segundo os rebanhos examinados na Microrregião de Manaus. Ressalte-se que todos os rebanhos avaliados apresentaram animais sororeagentes na IDLB, sendo observadas oscilações no percentual, que variaram de 3,0 até $30,0 \%$.

Na Figura 1 foram representados os resultados das 661 amostras de soro sangüíneo dos bovinos avaliados pela prova da IDLB, estratificados em diferentes faixas etárias, destacando-se as amostras sororeagentes. Os índices variaram de $1,8 \%(1 / 57)$ no grupo de animais com menos de seis meses de idade, até valores máximos de 14,4\% (24/167) em animais com mais de 72 meses de idade.

Na figura 2 foram configurados os valores obtidos pela realização da IDLB em amostras de soro sangüíneo de bovinos leiteiros machos e fềmeas, com mais de 12 meses de idade, criados na Microrregiāo de Manaus e avaliados neste estudo, os valores obtidos não apresentaram diferenças estatísticas significativas.

\section{DISCUSSÃO E CONCLUSÕES}

Nos últimos anos uma série de trabalhos tem enfatizando a maior especificidade dos testes ELISA e PCR para a deteç̧ão da infecção pelo VLB, entretanto, a praticidade, os baixos custos e a facilidade

${ }^{5}$ Kit Comercial - Rinder Lejkose - Antigen / Hoesdt Veterinär 
de leitura dos resultados associados a uma boa especificidade, sāo vantagens que fazem com que, a prova de IDGA permaneça sendo o teste de eleição para o levantamento epidemiológico da LEB na maioria dos países (Evermann \& Jackson, 1997). As limitações da IDGA para a deteç̧āo de anticorpos anti-VLB, sāo muito bem determinadas por diversos trabalhos de pesquisa (Hübner et al., 1996; Evermann \& Jackson, 1997) e amplamente conhecidas pela comunidade cientifica, possibilitando ao buiatra com base na análise dos resultados frente às situações especificas de cada animal estabelecer um diagnóstico da infecção perfeitamente seguro.
O estudo dos documentos da LEB tem demonstrado, que o maior impulsionamento das pesquisas, decorreu da comprovação das perdas econômicas ocasionadas pela moléstia, ora pelo descarte prematuro de animais (D’Angelino, 1991; Pollari et al., 1993), ora pelas perdas na produçāo e/ou pelos custos com assistência veterinária (Garcia et al., 1995), mas, principalmente, pela impossibilidade de comercializaçāo dos plantéis entre países (Sorensen, 1979; Thurmond, 1987; Johnson \& Kaneene, $1991 b)$.

Tabela 1. Resultados obtidos pelo teste de IDLB em 661 amostras de soro sangüíneo de bovinos leiteiros criados na microrregião de Manaus, Estado do Amazonas - 1999.

\begin{tabular}{lcc}
\hline SORO-REAÇÃO & Número absoluto & Número relativo (\%) \\
\hline Não-reagentes & 602 & 91,1 \\
Reagentes positivos & 59 & 8,9 \\
TOTAL & 661 & 100 \\
\hline
\end{tabular}

Tabela 2. Resultados obtidos pelo teste de IDLB em amostras de soro sangúíneo de bovinos estudados na microrregião de Manaus, segundo os rebanhos, Amazonas - 1999.

\begin{tabular}{ccccccc}
\hline NÚMERO DO REBANHO & \multicolumn{2}{c}{ Amostras colhidas } & \multicolumn{2}{c}{ Amostras reagentes } & \multicolumn{2}{c}{ Amostras não reagentes } \\
& N & $\%$ & $N^{\circ}$ & $\%$ & $N^{\circ}$ & $\%$ \\
\hline 1 & 45 & 6,8 & 4 & 8,9 & 41 & 91,1 \\
2 & 25 & 3,8 & 2 & 8,0 & 23 & 92,0 \\
3 & 17 & 2,5 & 3 & 17,6 & 14 & 82,4 \\
4 & 73 & 11,0 & 10 & 13,7 & 63 & 86,3 \\
5 & 95 & 14,4 & 6 & 6,3 & 89 & 93,7 \\
6 & 33 & 5,0 & 1 & 3,0 & 32 & 97,0 \\
7 & 39 & 6,0 & 4 & 10,3 & 35 & 89,7 \\
8 & 51 & 7,7 & 2 & 3,9 & 49 & 96,1 \\
9 & 18 & 2,7 & 2 & 11,1 & 16 & 88,9 \\
10 & 35 & 5,3 & 2 & 5,7 & 33 & 94,3 \\
11 & 10 & 1,5 & 3 & 30,0 & 7 & 70,0 \\
12 & 21 & 3,1 & 3 & 14,3 & 18 & 85,7 \\
13 & 6 & 0,9 & 1 & 16,7 & 5 & 83,3 \\
14 & 60 & 9,0 & 6 & 10,0 & 54 & 90,0 \\
15 & 39 & 6,0 & 6 & 15,4 & 33 & 84,6 \\
16 & 94 & 14,2 & 4 & 4,3 & 90 & 95,7 \\
TOTAL & 661 & 100,0 & 59 & 8,9 & 602 & 91,1 \\
\hline
\end{tabular}




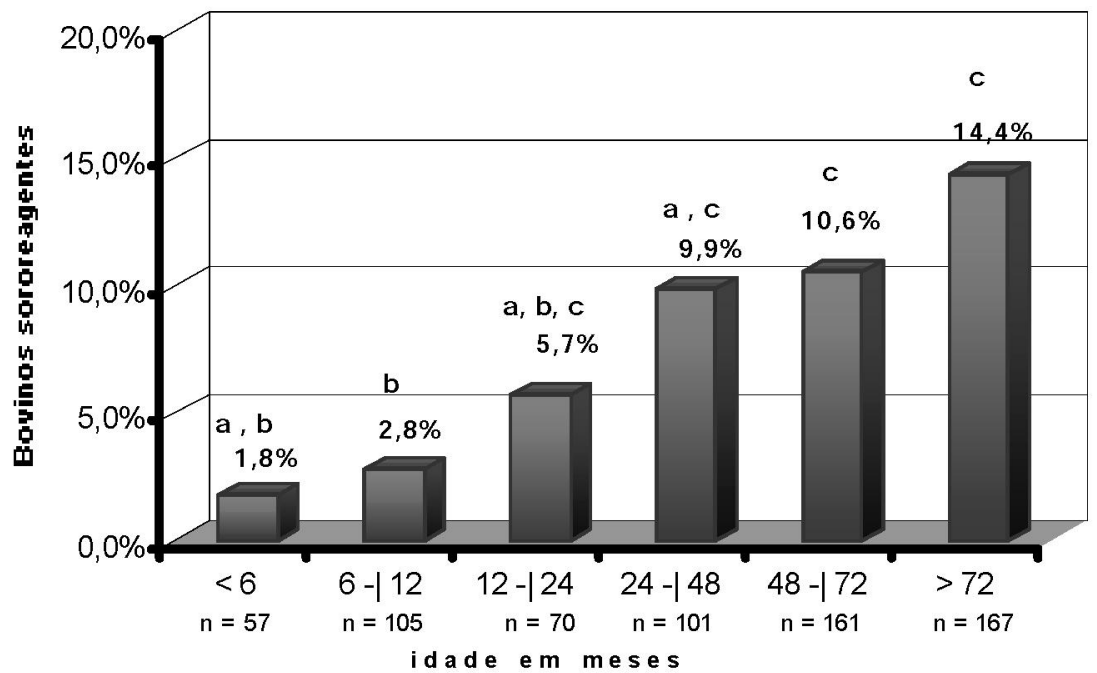

Figura 1. Bovinos leiteiros criados na microregião de Manaus sororeagentes ao antigeno GP - 51 da capsula do VLB, segundo as faixas etárias, Amazonas - 1999. a , b , c valores com letras não coincidentes indicam diferenças estatística significativa $(p<0,05)$

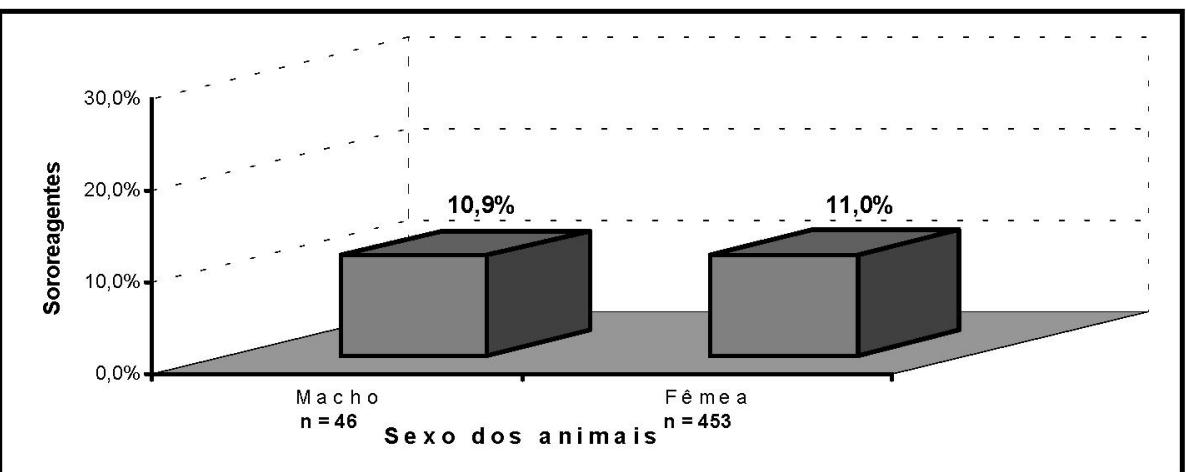

Figura 2. Bovinos leiteiros criados na microregião de Manaus sororeagentes ao antigeno GP - 51 da capsula do VLB, distribuidos segundo o sexo, Amazonas - 1999.

$\mathrm{Na}$ análise dos resultados dessa pesquisa, que buscou avaliar aspectos clínico epidemiológicos da LEB em rebanhos leiteiros criados na Microrregião de Manaus no Estado do Amazonas, observou-se que entre 661 amostras de soro sanguíneo avaliadas, 59 apresentaram reação positiva ao teste de IDLB, significando uma prevalência de $8,9 \%$ (59/ 661), comprovando a ocorrência da LEB no Estado do Amazonas, encontrando-se o seu agente etiológico amplamente disseminado em rebanhos leiteiros criados na Microrregião de Manaus, identificando-se bovinos sororeagentes em todos os rebanhos avaliados na pesquisa.

A exclusão dos animais que compuseram o grupo experimental dos bezerros com menos de seis meses de idade, nos quais não se poderia diferenciar os que foram infectados por via vertical daqueles que apresentassem 
anticorpos anti-VLB transferidos passivamente pela ingestāo do colostro (Burridge et al., 1982; Hübner et al., 1996), transformaria a população examinada, em uma amostragem de 604 animais, com 58 soropositivos, resultando numa taxa de prevalência de $9,6 \%(58 / 604)$ que representaria os bovinos seguramente infectados pelo VLB e criados na Microrregião de Manaus no Estado do Amazonas.

Dessa forma confirma-se a ocorrência da LEB, em 17 dos 26 Estados brasileiros: Acre, Alagoas, Amazonas, Bahia, Ceará, Goiás, Minas Gerais, Pará, Paraíba, Paraná, Pernambuco, Piauí ${ }^{6}$, Rio de Janeiro, Rio Grande do Norte ${ }^{7}$,Rio Grande do Sul, Rondônia e São Paulo.

O número total de animais submetidos à prova de IDLB no Brasil passou a ser de 26.797, sendo o número de animais sororeagentes igual a 7.399 , com prevalência nacional de $27,6 \%$, ocasionando uma diminuição no valor da prevalência da LEB, justificando-se pelo fato deste trabalho ter acrescentado um número considerável de amostras ao quadro nacional, porém com pequena quantidade de positivas.

Ao se comparar os resultados obtidos no Estado do Amazonas, com os obtidos em levantamentos semelhantes realizados em outros Estados da Região Norte, observou-se que a prevalência de anticorpos anti-VLB obtida $(8,9 \%)$ foi equivalente à referida por Abreu et al. (1990) no Estado do Acre (9,7\%) contudo, sendo significantemente menor que a obtida no Estado de Rondônia (23,0\%) no mesmo trabalho, e também, significativamente menor que a prevalência obtida por Molnar et al. (1999) no Estado do Pará (26,0\%). Portanto de acordo com os critérios estabelecidos por Shettigara et al. (1986), que classificaram os índices de prevalência em baixa (até 10\%), média (de 11 a 30\%) e alta (maior que 30\%), as prevalências da LEB, na Região Norte teriam a seguinte classificaçāo: o Amazonas e - Acre como Estados de baixa prevalência, e, Rondônia e Pará como Estados de média prevalência para a infecçāo pelo VLB.

As taxas equivalentes de prevalência da LEB obtidas, no levantamento realizado no Estado do Acre, poderiam ser atribuídas, principalmente, as semelhanças no nível de tecnificaçāo e a baixa densidade de animais presentes nos dois Estados. Os maiores percentuais de reagentes verificados no Estado de Rondônia estāo certamente relacionados ao grande afluxo de bovinos àquele Estado, oriundos, principalmente, das Regiões CentroOeste e Sudeste, onde a infecção pelo vírus da LEB apresenta altas prevalências.

Os resultados obtidos por Molnar et al. (1999),no Estado do Pará (26\%), mesmo em rebanhos de corte, eram de certa forma esperados, em vista da maior densidade de animais presentes naquele Estado e principalmente devido às características da pecuária praticada na regiāo com maior nível tecnológico e o freqüente trânsito de animais entre propriedades no próprio Estado e/ou entre propriedades de outros Estados principalmente das regiões Centro-Oeste e Nordeste.

A somatória dos resultados obtidos nos levantamentos da prevalência da LEB, através da prova de IDLB, realizados na Regiāo Norte,

\footnotetext{
${ }^{6}$ Silva, S. S. Comunicação pesscal. Teresina. Fauldade de Nedicina Veterinária - Ufiversidade Federal do Piann, 1999.

${ }^{7}$ Birgel, E. H. Comnicação pesscal. Săo Paulo. Faculdade de Medicina Veterinéria e Zoctecria - Universidade de São Palo, 2000.
} 
já incluídos os valores obtidos no Estado do Amazonas, demonstrou que dos 3449 bovinos examinados, 580 eram sororeagentes, representando uma prevalência média igual a 16,8\% (Abreu et al., 1990; Molnar et al., 1999) valor próximo a média de $11.7 \%$ calculada para a Regiāo Nordeste (Távora \& Birgel, 1991; Melo, 1991; Abreu, 1993; Birgel et al., 1999), equivalente a média de $18,4 \%$ calculada para a Regiāo Sul (Scarci et al., 1980; Kantec et al., 1983; Gomes et al., 1985; Flores et al, 1988; Flores et al., 1990; Carvalho, 1994) e, significativamente menor, do que a média de $39,4 \%$ obtida em levantamentos realizados na Região Sudeste (Alencar et al., 1979; Leite et al., 1980; Modena, 1981; Romero \& Rowe, 1981; Cunha et al., 1982; Birgel et al., 1982; Modena et al., 1984; Santos et al., 1985; Birgel et al., 1988; Birgel et al., 1991; D’Angelino, 1991; Birgel et al, 1993; Birgel Junior et al., 1995; Birgel et al., 1996; Melo et al., 1999) e também da prevalência de 35,6\% determinada em Goiás (Andrade \& Almeida, 1991), único Estado em que se fez a avaliação da prevalência da LEB, na Região Centro-Oeste.

Os índices médios de prevalência encontrados na Região Norte (16,8\%) insignificantemente maiores do que os da Região da Nordeste $(11,7 \%)$ e equivalentes aos da Regiāo Sul (18,4\%), podem ser explicados devido à influência exercida pelos grandes índices de prevalência observados nos Estados de Rondônia (23,0\%) e Pará (26,0\%), que aumentaram significativamente os valores das médias. A composição dos rebanhos de Rondônia, em sua grande maioria formados por animais oriundos das Regiões Centro-Oeste e Sudeste, associados a intensa circulaçāo de animais e ao considerável nível de tecnificação na criação dos rebanhos no Estado do Pará, são particularidades que justificam os elevados índices de prevalência observados.
Em relação ao número de rebanhos infectados na Microrregiāo de Manaus, surpreendentemente, observou-se que $100 \%$ dos rebanhos pesquisados apresentaram animais infectados pelo VLB, situação semelhante àquela descrita na Região Sudeste do País, onde a presença de rebanhos leiteiros negativos, praticamente não foi mais registrada, em semelhantes levantamentos (Alencar et al., 1979; Leite et al., 1980; Romero \& Rowe, 1981; Modena, 1981; Birgel et al., 1982; Santos et al., 1985; Birgel et al., 1988; Birgel et al., 1991; D'Angelino, 1991; Birgel Junior et al, 1995; Melo et al., 1999). Por sua vez, nas regiões Nordeste e Sul, encontraram-se rebanhos que não possuíam animais infectados pelo VLB (Kantec et al., 1983; Gomes et al., 1985; Flores et al., 1988; Flores et al., 1990; Távora, 1991; Melo, 1991; Abreu, 1993; Carvalho, 1994; Simões, 1998; Birgel et al., 1999).

A análise das variações das taxas de prevalência de anticorpos anti-VLB observadas nos bovinos criados na Microrregião de Manaus, Estado do Amazonas, avaliados nesta pesquisa, estratificados em seis faixas etárias, demonstrou que, a percentagem de bovinos sororeagentes aumentou significativamente com o evoluir da idade, com índices que variaram $1,8 \%$, nos animais com até 6 meses, a 14,4\% nos animais com mais de 72 meses de idade.

Tais resultados já eram esperados e vieram a concordar com as informações obtidas na literatura compulsada desde os escritos de Bendixen (1957), passando pelos trabalhos de Baumgartner et al. (1975); Ferrer et al. (1976); Stöber (1981); Burridge et al. (1982); Burny et al. (1985); Távora (1990); D’Angelino (1991); Melo (1991) Abreu (1993); Birgel Júnior (1995) até os levantamentos epidemiológicos mais recentemente publicados no Brasil (Simões, 1998; Birgel et al., 1999). 
Após estudo da literatura anteriormente descrita, pode-se afirmar que, a maior freqüência da infecção pelo VLB, nos animais mais velhos, não se deve a variação de susceptibilidade dos animais com o evoluir da idade, mas sim devido uma interação de fatores de influência, relacionando idade à longevidade ou tempo de permanência dos animais em rebanhos infectados, sendo natural a maior prevalência em animais idosos devido a maior probabilidade da ocorrência de contatos que resultem na transmissão e infecção viral.

Julgou-se necessário destacar, na análise dos resultados representados no Gráfico 1 , o aumento significativo dos índices de infecçāo pelo VLB, a partir dos 12 meses de idade. Os resultados, coincidem com a idade em que os animais desmamados de sobreano sāo incorporados aos rebanhos constituído por bovinos adultos, na maioria das propriedades estudadas, confirmando as conclusões que, embora a infecção intra-uterina possa perpetuar o vírus de uma geração a outra, este não é considerado o mais importante meio de transmissão da infecção (Mammerickx et al., 1978; Miller \& Van Der Maaten, 1979; Ferrer \& Piper, 1981; Jacobson et al., 1983; D'Angelino, 1991).

A análise dos resultados representados na figura 2 , demonstrou que a taxa de prevalência de machos púberes sororeagentes aos antígenos do VLB $(10,9 \%)$ foi menor do que as observadas nas fêmeas púberes $(11,0 \%)$, contudo, tal diferença não foi estatisticamente significante ao nível de $5 \%$.

Esta observação difere das afirmações encontradas por Távora (1990), Melo (1991) e Simões (1998) na Bahia, Pernambuco e Paraíba, respectivamente que verificaram índices de infecção estatisticamente maiores nas fêmeas do que nos machos, entretanto os resultados obtidos no Estado do Amazonas, foram semelhantes aqueles obtidos por Abreu (1993) no Ceará onde apesar dos machos apresentarem indices de anticorpos anti-VLB maiores que as fêmeas, estas diferenças não foram estatisticamente significcativas. Tal discrepância, provavelmente, está relacionada ao sistema de manejo adotado, pois nos rebanhos estudados nos Estados do Amazonas e Ceará os touros eram mantidos de forma permanente no rebanho, ao passo que nos outros estudos, adotava-se a inseminação artificial ou a monta controlada, permanecendo os machos isolados e sem contato livre e direto com os demais participantes do rebanho.

Experiências em países com grandes taxas de prevalência, como Estados Unidos e Canadá, têm demonstrado a necessidade de programas de controle muito mais prolongados e dispendiosos (Johnson et al., 1983; Brunner et al., 1997; Johnson \& Kaneene, 1991b). Portanto, é imperioso ressaltar que, apesar da ampla disseminação da LEB em todas as regiões geográficas do Brasil, comprovada pelos resultados obtidos neste trabalho associados aqueles das demais pesquisas realizadas no Brasil, o índice de prevalência nacional $(27,7 \%)$, considerado médio pela classificação de Shetigara et al., (1986), ainda nos favorece no sentido da obtenção de bons resultados desde que, em curto espaço de tempo, sejam criados programas oficias de controle e erradicação da doença.

\section{BIBLIOGRAFIA CITADA}

Abreu, J. M. G. 1993. Leucose Enzoótica dos Bovinos. Prevalência de anticorpos séricos anti-Virus da Leucose Bovina em animais criados na Bacia leiteira de Fortaleza, Estado do Ceará. Dissertação (Mestrado) - Faculdade de Medicina 
Veterinária e Zootecnia, Universidade de Sāo Paulo. São Paulo, 75p.

Abreu, J.M.G.; Araujo, W. P.; Birgel, E. H. Prevalência de anticorpos séricos anti Vírus da Leucose Bovina em animais criados na Bacia Leiteira de Fortaleza, Estado do Ceará. 1994. Arquivos da Escola de Medicina Veterinária da Universidade Federal da Bahia, v. 17: $67-89$

Abreu, V.L.V.; Modena, C.M.; Silva, J.A.; Moreira, E.C.; Figueiredo, M.M.N. 1990. Prevalência da leucose enzoótica bovina nos Estados de Rondônia e Acre. Arquivo Brasileiro de Medicina Veterinária e Zootecnia, 42 (3): 203-10

Alencar Filho, R.A.; Mazanti, M.T.; Saad, A.D.; Pohl, R. 1979. Levantamento preliminar da infecção pelo vírus da leucemia linfática crônica (L. L. C.) dos bovinos no Estado de São Paulo. O Biológico, $45(3 / 4): 47-54$

Andrade, J.R.A.; Almeida, M.M.R. 1991. Prevalência da Leucose Enzoótica Bovina na bacia leiteira de Goiânia, Goiás. A Hora Veterinária, Ano 10, n. 60: 49-53

Bendixen, H.J. 1957. Epizootiology, diagno sis and control of bovine leukosis. Bulletin international des Epizooties, 68: 73-99

Berquo, E.S.; Souza, J.M.P.; Gotlieb, S.L.D. 1981. Bioestatística. São Paulo: Ed. Pedagógica e Universitária. 350 p.

Birgel, E.H. 1982. Leucose Enzoótica dos bovinos adultos: aspectos clínicos e diagnóstico. In: Birgel, E.H.; Benesi, F.J. Patologia Clínica Veterinária. Sociedade
Paulista de Medicina Veterinária. São Paulo. p. 249-60.

Birgel, E.H.; Benesi, F.J.; D’Angelino, J.L.; Hagiwara, M.K.; Prado, M.S.S. 1982. Características leucométricas do sangue de bovinos de rebanhos acometidos por Leucose Enzoótica dos Bovinos Adultos. In: Semana de Veteriária da Faculdade de Medicina Veterinária e Zootecnia da Universidade de São Paulo, 1, Anais, Campinas. p. 73.

Birgel, E.H.; Benesi, F.J.; D’Angelino, J.L.; Hagiwara, M.K.; Prado, M.S.S. 1983. Considerações sobre a Leucose Enzoótica dos Bovinos Adultos em rebanhos leiteiros criados no Estado de São Paulo. II Aspectos relacionados a produção. In: Semana de Veteriária da Faculdade de Medicina Veterinária e Zootecnia da Universidade de São Paulo, 2, Anais, São Paulo. p.71.

Birgel, E.H.; D’Angelino, J.L.; Garcia, M.; Marçal, W.S. 1988. Estudo preliminar sobre a ocorrência da Leucose dos Bovinos Adultos em animais criados na região de Campinas. In: Conferência Anual da Sociedade Paulista de Medicina Veterinária, 43, Anais, Campinas. p.30.

Birgel, E.H.; D’Angelino, J. L.; Garcia, M.; Benesi, F.J.; Zogmo, M. 1991. A. Ocorrência da infecção causada pelo Vírus da Leucose Bovina no Estado de São Paulo. Brazilian Journal of Veterinary Research Animal Science, 28(1): 67-73

Birgel, E.H.; Távora, J.P.F.; Souza, P.M.; Birgel Junior, E.H. 1996. Prevalência de anticorpos séricos anti-vírus da Leucose 
dos Bovinos em zebuínos da raça Gir, criados no Estado de São Paulo. In: Congresso Brasileiro de Medicina Veterinária, 14, Anais, Goiânia. p.165.

Birgel, E.H.; Ayres, M.C.C.; Birgel Junior, E.H. 1999. Prevalência da leucose enzoótica dos bovinos, em animais criados na bacia leiteira do Estado de Alagoas, Brasil. In: Congresso Brasileiro de Buiatria, 3, Anais, Sāo Paulo. p.129.

Birgel Junior, E.H.; D’Angelino, J.L.; Benesi F.J.; Birgel, E.H. 1995. Prevalência da infecçāo pelo Vírus da Leucose dos Bovinos em animais da raça Jersey, criados no Estado de São Paulo. Pesquisa Veterinária Brasileira, 15 (4): 93-9

Brasil. Ministério da Agricultura. Focos de doenças das listas "A" e "B", segundo espécies animais e unidades da Federação - Brasil - 1983. Boletim de Defesa Sanitária Animal, 17 (1-4): 89.

Brenner, J.; Moss, S.; Moalem, U. 1994. A comparative study of the ELISA and AGID techniques for the detection of bovine leucosis virus antibodies in bovine serum and milk. Israel Journal of Veterinary Medicine, 49 (4): 165-7

Brunner, M.A.; Lein, D.H.; Dubovi, E.J. 1997. Experiences with the New York State bovine leukosis virus eradication and certification program. Veterinary Clinics of North America: Food Animal Practice, 13 (1): $143-0$

Burny, A.; Bruck, C.; Cleuter, Y.; Couez, D.; Deschamps, J.; Gregoire, D.; Ghysdael, J.; Mammerickx, M.; Marbaix, G.; Portelle, D. 1985. Bovine leukemia virus and en- zootic bovine leukosis. Onderstepoort Journal of Veterinary Research, 52 (3): 133-44

Burridge, M.J.; Thurmond, M.C.; Miller, J.M.; Schmerr, M.J.F.; Van Der Maaten, M.J. 1982. Duration of colostral antibodies to bovine leukemia virus by two sero logic tests. American Journal of Veterinary Research, 43 (10): 1866-7

Carvalho, L. 1994. Leucose Enzoótica dos Bovinos. Prevalência de anticorpos séricos anti-Virus da Leucose Bovina em bovinos da raça Holandesa Preto e Branca e zebuínos da raça Nelore, criados no Pólo Regional de Londrina, Estado do Paraná. Dissertação (Mestrado), Faculdade de Medicina Veterinária e Zootecnia, Universidade de São Paulo. São Paulo, 79p.

Centro Panamericano de Zoonosis (Buenos Aires). 1979. Procedimientos para estudios de prevalência de enfermedades crónicas por muestreo. Buenos Aires, 33p.

Cristescu, P.; Tetu, M.; Vior, E.; Begnescu, R.; Vior, C. 1987. Aspects of prenatal and postnatal serological and hematological diagnosis of Enzootic Leucosis in cows. Archiv Experimentelle Veterinärmedizin., 41 (5): 767-73

Cunha, R.G.; Teixeira, A.C.; Souza, D.M. 1982. Antígenos do Vírus da Leucose Bovina e anticorpos precipitantes em soros de bovinos. Pesquisa Agropecuária Brasileira, 17 (9): 1363-70

D’Angelino, J.L. 1991. Leucose enzoótica dos bovinos, estudo retrospectivo da performance produtiva e reprodutiva de animais infectados e não infectados. Dissertação 
(Livre Docência) - Faculdade de Medicina Veterinária e Zootecnia, Universidade de Sāo Paulo. São Paulo, 85p.

Ereno, D. 1988. Leucose Bovina requer atenção pois o perigo existe. Balde Branco, 24 (287): $19-20$

Evermann, J.F.; Jackson, M.K. 1997. Labora tory diagnostic tests for retroviral infections in dairy and beef cattle. Veterinary Clinics of North America: Food Animal Practice, 13 (1): 87-106

Ferrer, J.F.; Baliga, V.; Diglio, C. 1976. Recent studies on the characterization of the bovine leukemia virus (BLV); development of new methods for the diagnosis of BLV infection. Veterinary Microbiology, 1 (2): 159-84

Ferrer, J.F.; Marshak, R.R.; Abt, D.A.; Kenyon, S.J. 1979. Relationship between lymphosarcoma and persistent lymphocytosis in cattle: a review. Journal of the American Medical Association, 175 (7): 705-8

Ferrer, J.F. Bovine lymphosarcoma. 1980. The Compendium on Continuing Education for the Practicing Veterinarian, 2(11): 235-42

Ferrer, J.F.; Piper, C.E. 1981. Role of colostrums and milk in the natural transmission of the bovine leukemia virus. Cancer Research, 41 (12): 4906-9

Flores, E.F.; Weiblen, R.; Pereira, N.M.; Portolann, J.A.B.; Chielle, L.L. 1988. Prevalência de anticorpos contra o vírus da leucose bovina (VLB) no rebanho leiteiro de Santa Maria, R. S. Revista do Centro de Ciências Rurais, Santa Maria, 18 (1): $67-73$
Flores, E.F.; Weiblen, R.; Rebelatto, M.C. 1990. Aspectos epidemiológicos da infecção pelo vírus da leucose bovina (VLB) na região central do Rio Grande do Sul, Brasil. Hora Veterinária, v. 58: 25-9

Garcia, M.; D’Angelino, J.L.; Birgel, E.H. 1991. Leucose Bovina no Brasil. Comunicações Cientificas da Faculdade de Medicina Veterinária e Zootecnia da Universidade de São Paulo, 15 (1): 31-9

Garcia, M.; Bastos, P.A.S.; Barros Filho, I.R.; Libera, A.M.M.P.D.; Coutinho, S.D.A.; Ramos, M.C.C.; Lourenço, A.; Silva, M.M. 1995. Efeito da infecção pelo vírus da leucose na ocorrência de mastite em bovinos. A Hora Veterinária, 15

(88): $41-4$

Gomes, M.; Moojen, V.; Fernandes, J.C.T.; Ferreiro, L. 1985. Detecção de anticorpos contra o vírus da leucose enzoótica bovina (VLEB) em bovinos no Estado do Rio Grande do Sul. Arquivos da Faculdade de Veterinária da Universidade Federal do Rio Grande do Sul, v. 13: 15-22

Gonzales, E.T.; Norimine, J.; Valera, A.R.; Traveria, G.; Oliva, G.A. 1999. A rapid and sensitive diagnosis of bovine leukemia virus infection using the nested shuttle polymerase chain reaction. Pesquisa Veterinária Brasileira, 19 (2): 63-7

Jacobson, K.C.; Bull, R.W.; Miller, J.M.; Herdt, T.H.; Kaneene, J. B. 1983. Transmission of bovine leukemia virus: prevalence of antibodies in precolostral calves. Preventive Veterinary Medicine, 1 (3): 265-72

Jacobson, K.C.; Kaneene, J.B.; Miller, J.M. 1985. Comparison of the commercial agar gel immunodiffusion test and radio-immunoprecipitation assay for detection of 
antibodies to bovine leukemia virus. American Journal of Veterinary Research, 41 (7): 1430-33

Johnson, R.; Kaneene, J.B. 1991b. Bovine Leukemia Virus. Part IV Economic impact and control measures. Compendium on Continuing Education for the Practicing Veterinarian, 13 (11): 1727-37

Johnson, R.; Kaneene, J.B. 1992. Bovine Leukemia Virus and Enzootic Bovine Leukosis. Veterinary Bulletin, 62 (4): 287-314

Johnson, R.; Kaneene, J.B.; Gibson, C.D. 1983. Bovine Leukemia Virus: A herd based control strategy. Preventive Veterinary Medicine, 3 (4): 339-49

Jordāo, L.P. 1986. Leucose Enzoôtica Bovina. Gado Holandês, 50 (129): 42-3

Jordão, L.P. 1987. Regulamentação sanitária da Leucose Bovina na França. Gado Holandês, 52 (145): 107

Kantec, C.E.; Kruger, E.R.; Welte, V.R. 1983. Prevalência do vírus da leucose enzoótica bovina no rebanho leiteiro do Paraná. Pesquisa Veterinária Brasileira, 3 (4): 125 9

Leite, R.C.; Modena, C.M.; Moreira, E.C.; Abreu, J.J. 1980. Leucose enzoótica bovina em Minas Gerais. In: Congresso Brasileiro de Medicina Veterinária, 17, Anais. Fortaleza. p.207.

Lorenz, R.J.; Straub, O.C. 1987. The epidemiology of enzootic bovine leukosis. In: Burny, A.; Mammerickx, M. (eds.) Enzootic bovine leukosis and bovine leukemia virus. Martinus Nijhoff. Boston. p.51-68.
Mammerickx, M; Cormann, A.; Burny, A.; Dekegel, D.; Portelle, D. 1978. Eradication of enzootic bovine leukosis based on the detection of the disease by the gp $51 \mathrm{im}$ munodiffusion test. Annales de Recherches Veterinaires, 9 (4): 885-94

Martins, V.M.V. 1989. Leucose Enzoótica Bovina. In: Semana de Atualização em Bovinocultura, 3, Anais. Lages. p.118-32.

Melo, L.E.H. 1991. Leucose Enzoótica Bovina: prevalência da infecção em rebanhos leiteiros criados no Agreste Meridional do Estado de Pernambuco. Dissertaçāo (Mestrado) - Faculdade de Medicina Veterinária e Zootecnia, Universidade de São Paulo. São Paulo, 102 p.

Melo, L.E.H.; D’Angelino, J.L.; Schalch, U.M.; Araujo, W.P.; Pacheco, J.C.G.; Benatti, L.A.T. 1999. Ocorrência da leucose enzoótica bovina (LEB) em rebanhos produtores de leite $\mathrm{C}$ criados no Estado de São Paulo, Brasil. In: Congresso Brasileiro de Buiatria, 3, Anais. São Paulo. p.129.

Miller, J.M.; Van Der Maaten, M.J. 1979. Infectivity tests of secretions and excretions from cattle infected with bovine leukosis virus. Journal of the National Cancer Institute, 62 (2): 425-8

Modena, C.M. 1981. Leucose Enzoótica Bovina. I - Comparação entre métodos de diagnóstico. II - Evolução sorológica em bezerros. III - Interferência com a vacina anti-febre aftosa. Arquivos da Escola de Veterinária da Universidade Federal de Minas Gerais, 33 (3): 624-5

Modena, C.M.; Abreu, V.L.V.; Silva, J.A.; 
Moreira, E.C.; Azevedo, N.A.; Rehfeld, O.A.M. 1984. Leucose enzoótica bovina. I - Prevalência em rebanhos de alta linhagem no estado de Minas Gerais. Arquivo Brasileiro de Medicina Veterinária e Zootecnia, 36 (1): 39-45

Molnár, E.; Molnalár, L.; Carvalho, M.; Lima, E.S. 1999. Exames soro-epidemiológicos sobre a leucose enzoótica dos bovinos no Estado do Pará, Brasil. Revista Brasileira de Ciências Veterinárias, 6 (2): 92-7

Molnár, E.; Molnár, L.; Dias, T.H.; Silva, A.O.A.; Vale, W.G. 1999. Ocorrência da Leucose Enzoótica dos Bovinos no Estado do Pará, Brasil. Revista Brasileira Medicina Veterinária, 21 (4): 171-5

Oliveira, A.R. 1985. Leucose Bovina. Balde Branco, 20: p. 21-2

Olson, C.; Miller, J.M. 1987. History and terminology of enzootic bovine leukosis. In: Burny, A.; Mammerickx, M. (eds). Enzootic Bovine Leukosis and Bovine Leukemia Virus. Martinus Nijhoff Publishing. Boston. p. 3-11.

Pollari, F.L.; DiGiacomo, R.F.; Evermann, J.F. 1993. Use of survival analysis to compare cull rates between bovine leukemia virus seropositive and seronegative dairy cows. American Journal of Veterinary Research, 54 (9): $1400-3$

Romero, C.H.; Rowe, C.A. 1981. Enzootic bovine leukosis virus in Brazil. Tropical Animal Health and Production, 13 (2): 107-11

Romero, C.H.; Zanocchi, H.G.; Aguiar, A.A.; Abaracon, D.; Silva, A.G.; Rowe, C.A. 1982. Experimental transmission of enzootic bovine leukosis virus with blood and milk in the tropics. Pesquisa Veterinária Brasileira, 2(1): 9-15

Romero, C.H.; Abaracon, D.; Rowe, C.A.; Silva, A.G. 1984. Bovine Leukosis virus infectivity in Boophilus microplus ticks. The Veterinary Record, 115 (17): 440-1

Santos, J.L.; Faria, J.E.; Ribeiro, M.F.B.; Salcedo, J.H.P. 1985. Epidemiologia da Leucose Enzoótica Bovina no Estado de Minas Gerais. I - Prevalência de anticorpos na Zona da Mata. Arquivo Brasileiro de Medicina Veterinaria e Zootecnia, 37 (4): $359-68$

Scarci, R.M.; Bento, C.L.; Medeiros, E.L.; Guarenti, P.J. 1980. Avaliação dos testes sorológicos e hematológicos no diagnóstico da leucose bovina. In: Congresso Brasileiro de Medicina Veterinária, 17, Anais. Fortaleza. p.137.

Shettigara, P.T.; Samagh, B.S.; Lobinowich, E.M. 1986. Eradication of bovine leukemia virus infection in commercial dairy herds using the agar gel imunodifusion test. $\mathrm{Ca}$ nadian Journal of Veterinary Research, 50 (2): $221-6$

Sorensen, D.K. 1979. Economics of bovine leukosis. In: Proceedings of Bovine Leukosis Symposium. U. S. Department of Agriculture, Washington, DC. p5-15.

Stober, M. 1981. The clinical picture of the enzootic and sporadic forms of bovine leukosis. Bovine Practioner, v. 16: 119 129

Távora, J.P.F. 1990. Prevalência da infecção pelo Virus da Leucose Bovina em rebanhos leiteiros criados na região do pólo Itabuna, 
Estado da Bahia. Dissertação (mestrado). Faculdade de Medicina Veterinária e Zootecnia, Universidade de São Paulo. São Paulo, 106 p.

Távora, J.P.F.; Birgel, E.H. 1991. Prevalência da infecção pelo vírus da leucose bovina em rebanhos leiteiros criados na região do pólo de Itabuna, Estado da Bahia. Arquivos da Escola de Veterinária da Universidade Federal da Bahia, v. 14: 164-83
Thurmond, M.C. 1987. Economics of enzootic bovine leukosis. In: Burny, A.; Mammerickx, M. Enzootic Bovine Leukosis and Bovine Leukemia Virus. Martinus Nijhoff, Boston. p.71-84.

Submetido à publicação: 22/04/2002

Aceito: $31 / 07 / 2002$ 